\title{
CULTURA E CONSUMO: UMA EXPLICAÇÃO TEÓRICA DA ESTRUTURA E DO MOVIMENTO DO SIGNIFICADO CULTURAL DOS BENS DE CONSUMO
}

\section{RESUMO}

Numa sociedade de consumo, o significado cultural se move incessantemente de um ponto para outro. Na trajetória normal, o significado cultural se move primeiro do mundo culturalmente constituído para os bens de consumo e desses para o consumidor individual. Diversos instrumentos são responsáveis por esse movimento: a publicidade, o sistema de moda e quatro rituais de consumo. Este artigo analisa o movimento do significado cultural do ponto de vista teórico, demonstrando onde reside o significado cultural no sistema de consumo da América do Norte e os meios por onde o significado se transfere de um ponto do sistema para outro.

\section{Grant McCracken}

Harvard Business School

ABSTRACT Cultural meaning in a consumer society moves ceaselessly from one location to another. In the usual trajectory, cultural meaning moves first from the culturally constituted world to consumer goods and then from these goods to the individual consumer. Several instruments are responsible for this movement: advertising, the fashion system, and four consumption rituals. This article analyses the movement of cultural meaning theoretically, showing both where cultural meaning is resident in the contemporary North American consumer system and the means by which this meaning is transferred from one location in this system to another.

PALAVRAS-CHAVE Antropologia, bens de consumo, significado cultural, sistema de consumo.

KEYWORDS Anthropology, consumer goods, cultural meaning, consumer system. 
Os bens de consumo têm uma significância que vai além de seu caráter utilitário e seu valor comercial. Essa significância reside, em grande medida, na capacidade que têm os bens de consumo de carregar e comunicar significado cultural (Douglas e Isherwood, 1978; Sahlins, 1976). Durante a década passada, um diversificado grupo de estudiosos fez da significância cultural dos bens de consumo o foco de novos estudos acadêmicos (Belk, 1982; Bronner, 1983; Felson, 1976; Furby, 1978; Graumann, 1974-1975; Hirschman, 1980; Holman, 1978; Leiss, 1983; Levy 1978; McCracken, 1985c; Prown, 1982; Quimby, 1978; Rodman e Philibert, 1985; Schlereth, 1982; Solomon, 1983). Esses estudiosos estabeleceram um subcampo das ciências sociais que hoje se dedica com crescente clareza e abrangência ao estudo das relações "pessoa-objeto". Neste artigo, pretendo contribuir com uma perspectiva teórica para esse subcampo emergente, demonstrando que o significado carregado pelos bens tem uma qualidade móvel que as teorias prevalecentes não incorporam.

Uma grande limitação das atuais abordagens ao estudo do significado cultural dos bens de consumo é sua nãoobservação do fato de que esse significado está em constante trânsito. O significado cultural flui naturalmente entre suas diversas localizações no mundo social, auxiliado pelos esforços coletivos e individuais de projetistas, produtores, publicitários e consumidores. Esse movimento segue uma trajetória tradicional. De modo geral, o significado cultural é absorvido do mundo culturalmente constituído e transferido para um bem de consumo. O significado é, então, absorvido do objeto e transferido para um consumidor individual. Em outras palavras, o significado cultural se localiza em três lugares: no mundo culturalmente constituído, no bem de consumo e no consumidor individual, movendo-se numa trajetória com dois pontos de transferência: do mundo para o bem e do bem para o indivíduo. A Figura 1 resume essa relação. Proponho, neste artigo, analisar essa trajetória do significado, tomando um estágio por vez.

Aceitar a qualidade móvel do significado cultural numa sociedade de consumo deve ajudar a esclarecer dois aspectos do consumo na sociedade moderna. Primeiramente essa perspectiva nos incentiva a perceber consumidores e bens de consumo como estações na via do significado. Com isso, concentramo-nos em propriedades estruturais e dinâmicas que nem sempre foram enfatizadas. Em segundo lugar, a perspectiva da "trajetória" pede que enxerguemos fenômenos como a publicidade, o mundo da moda e os rituais de consumo como instrumentos do movimento do significado. Somos encorajados a reconhecer a presença de um sistema grande e forte no cerne da sociedade de consumo moderna, que confere a essa sociedade parte de sua coerência e flexibilidade enquanto age como fonte constante de incoerência e descontinuidade. Em suma, essa perspectiva pode ajudar a demonstrar parte da complexidade do comportamento de consumo de hoje e a revelar em maiores detalhes o que, exatamente, significa ser uma sociedade de consumo.

Figura 1 - Movimentação do significado

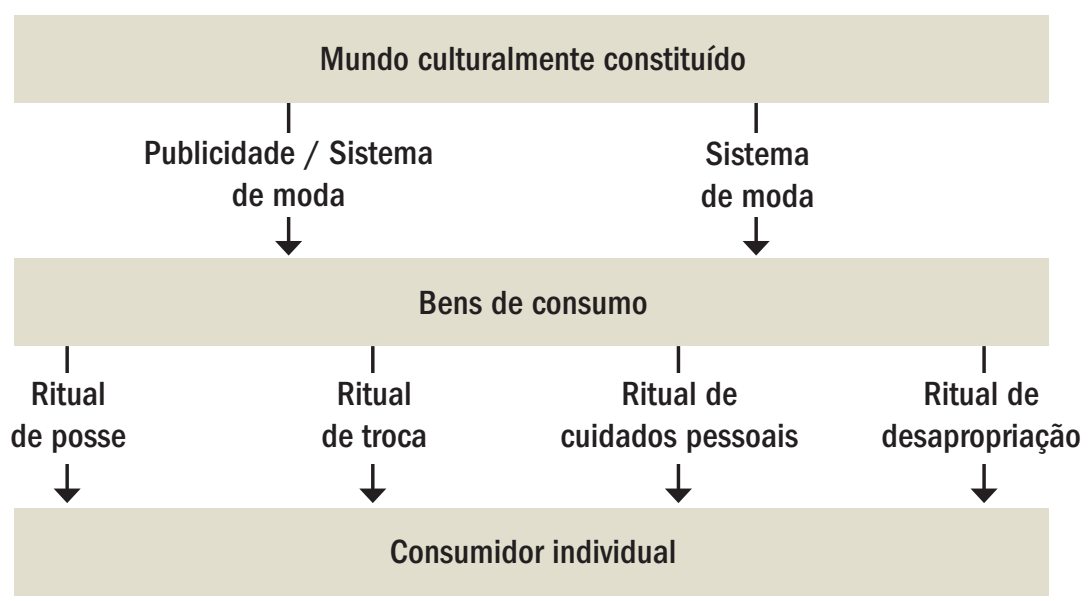

Legenda: Localização de significado $\longrightarrow$ Instrumento de transferência de significado 


\section{LOCALIZAÇÕES DO SIGNIFICADO CULTURAL: 0 MUNDO CULTURALMENTE CONSTITUÍDO}

A localização original do significado cultural que afinal reside nos bens de consumo é o mundo culturalmente constituído. Trata-se do mundo da experiência rotineira, em que o mundo dos fenômenos se apresenta, aos sentidos individuais, plenamente formado e constituído pelas crenças e premissas de sua cultura. A cultura constitui o mundo dos fenômenos de duas maneiras. Primeiramente a cultura é a "lente" pela qual o indivíduo enxerga os fenômenos; assim sendo, determina como os fenômenos serão apreendidos e assimilados. Em segundo lugar, a cultura é a "planta baixa" da atividade humana, determinando as coordenadas de ação social e atividade produtiva, e especificando os comportamentos e objetos que derivam de uma e de outra. Na qualidade de lente, determina como o mundo é visto. Na de planta baixa, determina como o mundo será moldado pelo esforço humano. Em suma, a cultura constitui o mundo, suprindo-o de significado. Esse significado pode ser caracterizado em termos de dois conceitos: categorias culturais e princípios culturais.

\section{Categorias culturais}

Categorias culturais são as coordenadas fundamentais do significado (McCracken, 1985a), representando as distinções básicas que uma cultura usa para dividir o mundo dos fenômenos. Por exemplo, todas as culturas especificam categorias de tempo. Em nossa cultura, essas categorias incluem um complexo sistema que pode discriminar entre unidades breves como um "segundo", ou longas como um "milênio". Nossa cultura também faz distinções menos precisas, mas não menos significativas, entre tempo de lazer e tempo de trabalho, tempo sagrado e tempo profano, etc. As culturas também especificam categorias de espaço. Em nossa cultura, essas categorias incluem tanto a mensuração quanto a "ocasião". As culturas também segmentam em categorias a flora, a fauna e o relevo de mundos natural e sobrenatural. As categorias mais importantes talvez sejam as que as culturas criam para a comunidade humana - as distinções de classe, status, gênero, idade e ocupação.

As categorias culturais de tempo, espaço, natureza e pessoa compõem um vasto corpo de categorias, criando um sistema de distinções que organiza o mundo dos fenômenos. Cada cultura estabelece sua própria visão particular do mundo, fazendo, assim, com que entendimentos e regras sejam apropriados num contexto cultu- ral e absurdamente impróprios em outro. Uma cultura estabelece um conjunto privilegiado de termos dentro do qual nada parece estranho ou ininteligível para o membro da cultura e fora do qual não há ordem, sistema, premissa segura e compreensão imediata. Em suma, ao investir o mundo de seu próprio significado particular, a cultura "constitui" o mundo. É de um mundo assim constituído que decorre o significado destinado aos bens de consumo.

\section{Categorias culturais da América do Norte contemporânea}

Vale notar que as categorias culturais da América do Norte de hoje parecem ter características singulares. Primeiro, gozam de uma indeterminação que não se costuma ver em outras circunstâncias etnográficas. Por exemplo, as categorias culturais de pessoa são marcadas por uma persistente e notável falta de clareza, assim como também o são as de idade. Em segundo lugar, possuem uma qualidade aparentemente "eletiva". Dedicada como é à liberdade individual, a sociedade norte-americana de hoje permite que seus membros declarem por seu exclusivo critério as categorias culturais que ocupam num dado momento. No exercício dessa liberdade, certos adolescentes declaram-se adultos, membros da classe trabalhadora declaram-se parte da classe média, velhos declaram-se jovens e assim por diante. A participação numa categoria, que na maioria das culturas é algo rigidamente especificado e policiado, é, em nossa cultura, muito mais ligada à escolha pessoal. Em nossa cultura, os indivíduos são, em grande medida, aquilo que afirmam ser, mesmo quando tais alegações sejam implausíveis de um ponto de vista sociológico objetivo.

É preciso observar uma terceira característica das categorias culturais da América do Norte contemporânea: elas estão sujeitas a mudanças constantes e aceleradas. A qualidade dinâmica das categorias culturais norte-americanas de hoje favorece, evidentemente, a sua indeterminação. E, mais importante, esse dinamismo também sujeita nossas categorias culturais aos esforços manipulativos do indivíduo. Os grupos sociais podem procurar alterar sua posição no esquema categórico, enquanto os marqueteiros podem procurar estabelecer ou encorajar uma nova categoria cultural de pessoa (por exemplo, adolescentes, yuppies) para criar um novo segmento de mercado. As categorias culturais da América do Norte contemporânea estão sujeitas a ser repensadas e reorganizadas pelas diversas partes. 


\section{A materialização das categorias culturais}

As categorias culturais constituem a matriz conceitual de um mundo culturalmente constituído. elas determinam como esse mundo será segmentado em parcelas distintas e inteligíveis, e como essas parcelas serão organizadas em um sistema maior e coerente. Por mais importantes que sejam, contudo, as categorias culturais não têm presença material no mundo que organizam, sendo as plataformas sobre as quais o mundo se sustenta, portanto, invisíveis. Mas as categorias culturais são constantemente materializadas pela prática humana. Agindo de acordo com a planta baixa da cultura, os membros de uma comunidade realizam constantemente categorias no mundo. Os indivíduos representam continuamente distinções categóricas, de tal modo que o mundo que criam seja condizente com o que imaginam. Num certo sentido, os membros de uma cultura estão constantemente engajados na construção - constituição - do mundo em que vivem.

Um dos meios mais importantes pelos quais as categorias culturais se materializam está nos objetos materiais de uma cultura. Como veremos em breve, os objetos são criados de acordo com a planta baixa de uma cultura e, nessa medida, dão matéria e substância às categorias dessa planta baixa. Assim, os objetos contribuem para a construção do mundo culturalmente constituído justamente porque registram de maneira vital e tangível um significado cultural que sem eles seria intangível. Com efeito, não é exagero dizer que os objetos têm uma função "performativa" (Austin, 1963; Tambiah, 1977) na medida em que dão ao significado cultural uma concretude que ele do contrário não teria para o indivíduo. O significado cultural que organize um mundo torna-se parte visível e demonstrável de tal mundo por meio dos bens.

O processo por meio do qual uma cultura manifesta suas categorias culturais vem sendo estudado com certo grau de detalhamento pelos antropólogos. A antropologia estrutural forneceu um esquema teórico para esse estudo, e diversas ramificações, como as antropologias da arte, do vestuário, da moradia e da cultural material, forneceram áreas de investigação específicas. Por conta desses esforços, há, hoje, um entendimento teórico claro da maneira como os meios lingüísticos e especialmente os não lingüísticos expressam categorias culturais (Barthes, 1967; Saussure, 1966; Levi-Strauss, 1963, p. 116; Sahlins, 1976). Há, também, uma ampla gama de investigações empíricas das áreas de organização espacial (Doxtater, 1984), de moradia (Fernandez, 1966; Greenberg, 1975), de vestuário (Adams, 1973; McCracken, 1986; Schwarz, 1979), ornamental (Drewal, 1983), tecnológica (Lechtman e Merrill, 1977) e alimentar (Appadurai, 1981; Douglas, 1971; Ortner, 1978). Esse estudo da cultura material tem ajudado a demonstrar como o mundo é provido de objetos materiais que contribuem para a sua constituição cultural e a refletem - como as categorias culturais são materializadas.

\section{A materialização das categorias culturais em bens}

Os bens podem ser vistos como uma oportunidade de exprimir o esquema categórico estabelecido por uma cultura. Os bens constituem uma oportunidade de dar matéria a uma cultura. Como qualquer outra espécie de cultura material, os bens permitem que os indivíduos discriminem visualmente entre categorias culturalmente especificadas, codificando essas categorias sob a forma de um conjunto de distinções materiais. As categorias de pessoas divididas em parcelas de idade, sexo, classe e ocupação podem ser representadas num conjunto de distinções materiais por meio de bens. As categorias de espaço, tempo e ocasião podem, também, ser refletidas nesse meio de comunicação. Os bens ajudam a dar substância à ordem da cultura.

Diversos estudos têm examinado a maneira como os bens agem nessa materialização. O estudo de Sahlin (1976) sobre o simbolismo dos bens de consumo norte-americanos examina os "sistemas" de alimentos e vestuário, e demonstra sua correspondência com categorias culturais de pessoa. O estudo de Levy (1981) sobre a correspondência entre tipos de alimento e categorias culturais de sexo e idade na sociedade americana é outro excelente exemplo de como é possível abordar as informações demográficas incorporadas nos bens de um ponto de vista estruturalista. Esses dois estudos demonstram que a ordem dos bens se molda a partir da ordem da cultura. Os dois estudos também demonstram que grande parte do significado dos bens pode ter suas raízes nas categorias em que uma cultura segmenta o mundo. A materialização de categorias de classe por bens de consumo foi considerada por Belk, Mayer e Bahn (1981), Coleman (1983), Davis (1956), Form e Stone (1957), Goffman (1951), Sommers (1963), Vershure, Magel e Sadalla (1977) e Warner e Lunt (1941). A materialização de categorias de gênero não tem sido tão bem examinada, mas parece estar atraindo mais atenção acadêmica (Allison, et al. 1980; Belk, 1982; Hirschman, 1984; Levy, 1959). A materialização de categorias etárias também parece estar merecendo mais atenção (Disman, 1984; Olson, 1985; Sherman e Newman, 1977-1978; Unruh, 1983). 


\section{Princípios culturais}

O significado cultural também consiste em princípios culturais. No caso dos princípios, o significado está nas idéias ou valores que determinam como os fenômenos culturais são organizados, avaliados e interpretados. Se as categorias culturais resultam da segmentação do mundo por uma cultura em parcelas distintas, os princípios culturais são as idéias organizadoras por meio das quais se dá a segmentação. Os princípios culturais são as premissas básicas que permitem que todos os fenômenos culturais sejam distintos, classificados e inter-relacionados. Como idéias norteadoras do pensamento e da ação, os princípios culturais encontram expressão em todos os aspectos da vida social, e não menos nos bens.

Os princípios culturais, assim como as categorias culturais, ganham substância na cultura material em geral e nos bens de consumo em particular. Vale observar que as categorias culturais e os princípios culturais presumem-se uns aos outros, e sua expressão em bens é necessariamente simultânea. Assim, os bens são incapazes de significar umas sem significar os outros. Quando os bens mostram distinção entre duas categorias culturais, fazem-no codificando algo do princípio segundo o qual as duas categorias se distinguem. Assim, a vestimenta que distingue homens de mulheres ou a classe alta da baixa também revela algo da natureza das diferenças que se presume haver entre essas categorias (McCracken, 1985c). O vestuário comunica tanto a presunção da "delicadeza" feminina quanto da "força" masculina, ou tanto a presunção de "refinamento" da classe alta quanto a de "vulgaridade" de outra, mais baixa. Aparentemente, as categorias de classe e sexo nunca são comunicadas sem essa indicação de como e por que se dá a distinção. O mundo dos bens, ao contrário do da linguagem, nunca se engaja em uma simples sinalização de diferença. Na verdade, os bens são sempre mais comunicativos e reveladores. No mundo dos bens, os sinais sempre são mais motivados e menos arbitrários do que no mundo da linguagem.

Os princípios culturais da América do Norte de hoje têm a mesma qualidade indeterminada, mutável e eletiva que as categorias culturais. Princípios como o "naturalismo" podem cair em desuso numa década e ser reabilitados e elevados a um novo lugar de importância noutra, como ocorreu na década de 1960 . O princípio de "desarmonia", tão útil para a estética punk, já foi não um princípio, mas apenas um termo aplicado a fenômenos que de alguma maneira fugiam à aplicação bem-sucedida de outro princípio. A literatura etnográfica sobre o significado dos objetos enquanto princípio encontra-se em Adams (1973), Drewal (1983), Fernandez (1966) e
McCracken (1982a). Não há abundância de literatura que demonstre a presença e a natureza do significado dos objetos como princípio na sociedade norte-americana de hoje. Levy (1981) faz breve referência à questão, assim como Sahlins (1976), e a idéia é abordada implicitamente no trabalho de Lohof (1969) sobre o significado carregado pelos cigarros Marlboro. A idéia também emerge na tentativa de sociólogos de fazer dos objetos um índice de prestígio e classe. Por exemplo, Laumann e House (1970) procuraram estabelecer o significado dos móveis domésticos recorrendo aos princípios de "moderno" e "tradicional". Felson, em seu estudo dos "estilos de vida material" (1976) postulou algo a que chamou "fator bricabraque", enquanto Davis (1958) cunhou o termo "Bauhaus ajaponesado" para caracterizar um determinado princípio de arquitetura de interiores. O princípio de "ciência" (ou, com mais precisão, a preocupação com o domínio da técnica sobre a natureza e a confiança de que os assuntos humanos podem ser transformados de maneira benigna por meio da inovação técnica) foi um dos motivos favoritos dos eletrodomésticos e automóveis na América do Norte das décadas de 1950 e 1960 (Csikszentimihalyi e Rochberg-Halton, 1981, p. 52). Estudiosos do ramo da cultura material dos estudos americanos e da história da arte fizeram as mais notáveis contribuições para essa área (Quimby, 1978; Schlereth, 1982). Prown (1980) e Cohen (1982), por exemplo, examinaram os princípios evidentes na movelaria americana.

Fica claro em todos os casos que, assim como as categorias culturais, os princípios culturais se materializam em bens de consumo e que esses bens, assim carregados, nos ajudam a compor o mundo culturalmente constituído. As categorias culturais e os princípios culturais organizam o mundo dos fenômenos e os esforços de uma comunidade para manipular esse mundo. Os bens materializam tanto categorias quanto princípios e, portanto, entram no mundo culturalmente constituído tanto como objeto quanto como objetificação desse mundo. Em suma, os bens são tanto as criações como os criadores do mundo culturalmente constituído.

\section{INSTRUMENTOS DE TRANSFERÊNCIA DE SIGNIFICADO: DO MUNDO PARA $O$ BEM}

O significado reside primeiro no mundo culturalmente constituído. Para passar a residir nos bens de consumo, precisa ser destacado desse mundo e transferido para os bens. Esta seção pretende examinar duas das instituições hoje usadas como instrumentos da transferência de sig- 
nificado: a publicidade e o projeto de produto tal como praticados no sistema da moda.

\section{Publicidade}

A publicidade funciona como método em potencial de transferência de significado, reunindo o bem de consumo e uma representação do mundo culturalmente constituído no contexto de uma peça publicitária. O diretor de criação de uma agência publicitária procura ligar esses dois elementos de tal maneira que o espectador/leitor perceba entre eles uma similaridade essencial. Quando essa equivalência simbólica é estabelecida com sucesso, o espectador/leitor atribui ao bem de consumo determinadas propriedades que sabe existirem no mundo culturalmente constituído. As propriedades conhecidas do mundo culturalmente constituído passam, assim, a residir nas propriedades desconhecidas do bem de consumo, e se realiza a transferência de significado do mundo para o bem.

A mecânica de tão complicado processo merece exposição mais detalhada. O diretor de criação tem por objetivo realizar uma conjunção eficaz de dois elementos, um dos quais especificado por um cliente. Na maioria dos casos, o cliente confia ao diretor um bem de consumo cujas propriedades físicas e embalagem são fixas e não sujeitas a manipulação. O segundo elemento, a representação do mundo culturalmente constituído, sofre restrições e é livre em proporções praticamente iguais. O cliente, por vezes fiando-se em pesquisas de mercado e assessoria de marketing, especifica as propriedades buscadas para o bem de consumo. Armado dessas especificações, o diretor de criação agora goza de amplo controle decisório. Sujeito apenas às restrições negativas das limitações de verba e às restrições positivas de uma imagem contínua da marca, ele está livre para fornecer as propriedades simbólicas desejadas de qualquer uma dentre um número quase infinito de maneiras.

Esse processo consiste numa longa e elaborada série de escolhas (Dyer, 1982; McCracken, 1984; Sherry, 1985; Williamson, 1978). A primeira delas é difícil: o diretor deve identificar com clareza suficiente para seus propósitos as propriedades desejadas para o bem em questão. Esse procedimento por vezes resulta num período de complicado debate entre o diretor e o cliente, em que as partes alternam-se entre conduzir e seguir a outra, aguçando sua percepção das propriedades pretendidas para o bem de consumo. Em todos os casos, a agência de publicidade estabelecerá seu próprio processo consultivo para obter clareza suficiente para prosseguir. A segunda escolha do processo é igualmente difícil, mas talvez menos sujeita a consultas. Aqui, o diretor precisa decidir onde as propriedades desejadas para o anúncio residem no mundo culturalmente constituído. Ele tem à sua disposição um vasto espectro de possibilidades dentre as quais pode escolher. É preciso optar por um lugar, e a primeira escolha deve ser entre dar ao anúncio uma ambientação fantástica ou natural. Escolhida esta última, é preciso decidir se o ambiente será interno ou externo, urbano ou rural, cultivado ou selvagem. Também é preciso escolher a hora do dia e a época do ano. Se o anúncio for mostrar pessoas, é preciso escolher seu sexo, idade, classe, status e ocupação, e seu figurino, postura física e estados afetivos devem ser especificados (Goffman, 1979). Esses são os elementos do mundo culturalmente constituído que podem ser evocados no anúncio.

É preciso notar que esse processo de seleção pode ser bem ou mal realizado, de acordo com a habilidade e o treinamento do diretor. Não há um caminho simples que leve das propriedades desejadas para o bem de consumo até os elementos do mundo culturalmente constituído capazes de evocá-las num anúncio. Como observam os publicitários, trata-se de um processo criativo em que as escolhas mais adequadas são mais vislumbradas do que calculadas. Imprecisões e erros desse processo criativo são não apenas possíveis, mas mesmo abundantes. É preciso notar também que o processo de seleção, por ser criativo, avança tanto no nível inconsciente quanto no consciente. Os diretores nem sempre estão plenamente cientes de como e por que se fez uma escolha, mesmo quando essa seleção se apresenta atraente e necessária (por exemplo, Arlen, 1980, p. 22 e 119).

Em suma, o diretor precisa escolher dentre alternativas que foram criadas pela rede de categorias e princípios culturais que constituem o mundo de uma cultura. As alternativas escolhidas refletirão as categorias e princípios que, segundo decida o diretor, melhor refletem o significado aproximado que o cliente busca para o produto. Uma vez concluídos esses dois processos de escolha, começa um terceiro. O diretor precisa decidir como, exatamente, o mundo culturalmente constituído será representado no anúncio. Esse processo consiste em rever todos os objetos que dão substância ao significado escolhido e decidir quais deles serão usados para evocar tal significado no anúncio. Finalmente, o diretor precisa decidir como apresentar o produto em seu contexto altamente planejado. Convenções fotográficas e visuais serão usadas para dar ao espectador/leitor uma oportunidade de vislumbrar uma equivalência essencial entre os dois elementos de mundo e objeto. O diretor precisa unir esses dois elementos numa conjunção que encoraje identificação metafórica de igualdade pelo consumidor em potencial. Mundo e 
bem precisam parecer gozar de uma harmonia especial - precisam ser vistos como coisas que combinam. O processo de transferência se dá quando o espectador/leitor percebe essa igualdade (depois de uma ou mais exposições aos estímulos). O significado se desloca do mundo culturalmente constituído para o bem de consumo. Tal bem agora representa um significado cultural que previamente desconhecia.

Imagens visuais e matéria verbal parecem assumir uma relação muito especial nesse processo de transferência. É principalmente o aspecto visual de um anúncio que liga o mundo e o objeto quando se busca uma transferência de significado. A matéria verbal serve principalmente como uma espécie de dica que instrui o espectador/leitor a respeito das propriedades salientes que se pretende expressar com a parte visual do anúncio. O texto (especialmente manchetes) explicita aquilo que a imagem já traz implícito. O texto dá instruções para ler a parte visual do anúncio. O componente verbal permite que o diretor conduza a atenção do espectador/leitor exatamente para as propriedades significativas que se quer transferir (cf. Barthes, 1983; p. 33-39; Dyer, 1982, p. 139-182; Garfinkle, 1978; Moeran, 1985).

Tudo isso deve agora estar bem decodificado pelo espectador/leitor. Vale enfatizar que o espectador/leitor é o autor final do processo de transferência. O diretor promove a conjunção do mundo e do bem de consumo e sugere sua similaridade essencial. Cabe ao espectador/ leitor enxergar essa similaridade e proceder à transferência das propriedades significativas. Nesse sentido, o espectador/leitor é participante essencial do processo de transferência de significado, como observa Williamson (1978, p. 40-70). O espectador/leitor precisa concluir o trabalho do diretor.

A publicidade é um meio pelo qual o significado se derrama constantemente do mundo culturalmente constituído sobre os bens de consumo. Por meio da publicidade, bens novos e velhos abrem mão de antigos significados e adquirem outros, novos, constantemente. Como participante ativo desse processo, o espectador/leitor se mantém informado do estado e do estoque atuais do significado cultural existentes nos bens de consumo. Nesse sentido, a publicidade serve como dicionário de significados culturais correntes. Em grande parte, a publicidade mantém uma consistência entre o que Sahlins (1976, p. 178) chama de "ordem da cultura" e "ordem dos bens".

\section{O sistema de moda}

O sistema de moda é menos freqüentemente observado, estudado e compreendido como instrumento de mo- vimentação de significado, mas também serve como o meio em que os bens são sistematicamente investidos e desprovidos de propriedades significativas. O sistema de moda é um instrumento de movimentação de significado um pouco mais complicado do que a publicidade. No caso desta, a movimentação se dá por meio dos esforços de uma agência de publicidade para extrair significado do mundo culturalmente constituído e transferi-lo para um bem de consumo por meio de um anúncio. No caso do sistema de moda, o processo tem mais fontes de significado, agentes de transferência e meios de comunicação. Parte dessa complexidade adicional pode ser captada observando que o mundo da moda opera de três maneiras diferentes para transferir significado para os bens.

Em uma capacidade, o sistema de moda realiza uma transferência de significado do mundo culturalmente constituído para os bens de consumo bastante semelhante, em caráter e efeito, à transferência realizada pela publicidade. O mesmo esforço de unir aspectos do mundo a um bem de consumo fica evidente em revistas e jornais, e busca-se o mesmo processo de similaridade vislumbrada. Nessa capacidade, o sistema de moda toma novos estilos de vestuário ou utilidades domésticas e os associa a categorias e princípios culturais estabelecidos, movendo significados do mundo culturalmente constituído para o bem de consumo. Esse é o aspecto mais simples da capacidade de distribuição de significado do sistema de moda, ironicamente considerado por Barthes (1983) como complexo e difícil de esclarecer.

Numa segunda capacidade, o sistema de moda efetivamente inventa novos significados culturais de maneira modesta. Essa invenção é realizada por formadores de opinião, que ajudam a moldar e refinar os significados culturais existentes, encorajando a reforma de categorias e princípios culturais. Trata-se de formadores de opinião distantes: pessoas que, por força de berço, beleza ou realizações, têm-se em alta conta. Com efeito, já se sugeriu que a inovação do significado é desencadeada pela apropriação imitadora por parte de pessoas de menor status social (McCracken, 1985c; Simmel, 1904). Classicamente, as pessoas de elevado prestígio vêm de uma elite social convencional: as classes altas. Essas classes originaram, por exemplo, o "preppie look", que recentemente se disseminou ampla e profundamente. Mais recentemente, os formadores de opinião têm vindo de um grupo de personagens despudoradamente nouveau riche que hoje domina as novelas noturnas, como Dallas e Dinasty, e que parece ter influenciado os hábitos de consumo e estilo de vida de tantos norte-americanos. Os astros do cinema e da música 
popular, reverenciados por seu prestígio, sua beleza e, às vezes, talento, também formam um grupo relativamente novo de formadores de opinião. Todos esses novos formadores de opinião inventam e distribuem uma espécie de significado que tem sido criada, em grande parte, a partir de coordenadas culturais predominantes estabelecidas por categorias culturais e princípios culturais. Esses formadores de opinião são permeáveis a inovações culturais, que repassam aos subordinados que os imitam.

Numa terceira capacidade, o sistema de moda se engaja em uma reforma radical dos significados culturais. Parte do significado cultural nas sociedades industriais ocidentais está sempre sujeita a mudança constante e profunda. Essa instabilidade radical do significado se deve ao fato de que as sociedades ocidentais, nos termos de Claude LeviStrauss (1966, p. 233-234), são "sociedades quentes". As sociedades ocidentais aceitam de bom grado, e até incentivam, as mudanças radicais que resultam de esforços humanos deliberados e do efeito de forças sociais anônimas (Braudel, 1973, p. 232; Fox e Lears, 1983; McCracken, 1985d; McKendrick, Brewer e Plumb, 1982). Com isso, o significado cultural numa sociedade quente, ocidental, industrial e complexa passa constantemente por mudanças sistemáticas. Em contraposição a virtualmente todo precedente etnográfico, os membros de tal sociedade vivem num mundo deliberada e continuamente em transformação (McCracken, 1985b). De fato, não seria exagero dizer que as sociedades quentes exigem mudanças e delas dependem para a alimentação de determinados setores econômicos, sociais e culturais de seu mundo (Barber e Lobel, 1953; Fallers, 1961). O sistema de moda é um dos dutos que captam e movimentam significados culturais altamente inovadores.

Os grupos responsáveis pela reforma radical do significado cultural são aqueles que existem à margem da sociedade, como os hippies, os punks e os gays (Blumberg, 1974; Field, 1970; Meyersohn e Katz, 1957). Tais grupos inventam um significado cultural muito mais radical e inovador do que seus parceiros de status elevado na liderança da difusão de significados. Com efeito, esses grupos inovadores representam uma ruptura em relação às convenções culturalmente constituídas da sociedade norte-americana contemporânea. Ilustram a tendência peculiarmente ocidental de tolerância a violações dramáticas das normas culturais. Esses grupos redefiniram as categorias culturais, ainda que pelo processo negativo de violação de categorias culturais como idade e prestígio (hippies e punks), ou gênero (gays). As categorias culturais redefinidas e diversos princípios culturais a elas associados entraram para o sistema cultural. Os grupos inovadores tornam-se "fornecedores de significado" mesmo quando são devotados à subversão da ordem estabelecida (hippies, por exemplo) ou estão determinados a não permitir que suas invenções culturais sejam absorvidas pelo sistema (punks, por exemplo; cf. Hebdige, 1979; Martin, 1981).

Se as fontes de significado cultural são dinâmicas e numerosas, também o são os agentes que coletam significado cultural e realizam sua transferência para os bens de consumo. No caso do sistema de moda, os agentes formam duas categorias principais: (1) projetistas de produto e (2) jornalistas de moda e observadores sociais. Os projetistas de produto podem, por vezes, ser os indivíduos altamente visíveis que se estabelecem como árbitros do desenho de vestuário em centros de moda como Paris ou Milão e se fazem cercar de um culto à personalidade. Outros projetistas de produto, como arquitetos e decoradores, às vezes obtêm estatura mais ou menos comparável e exercem influência igualmente internacional (Kron, 1983). Mais freqüentemente, contudo, são desconhecidos fora de seus próprios setores (Clark, 1976; Meikle, 1979; Pulos, 1983). Bom exemplo são os projetistas de automóveis de Detroit, bem como os criadores de produtos dos setores de mobiliário e utilidades domésticas, sendo Raymond Loewy uma exceção que confirma a regra.

A segunda categoria de agentes consiste em jornalistas de moda e observadores sociais. Os jornalistas de moda podem pertencer aos meios impresso ou filmado e podem ter um perfil de maior ou menor destaque. Os observadores sociais podem ser jornalistas que estudam e os documentam novos desdobramentos sociais - como Lisa Birnbach (1980), Kennedy Fraser (1981), Tom Wolfe (1970), Peter York (1980); ou podem ser acadêmicos dedicados a uma investigação assemelhada de um ponto de vista algo diferente - como Roland Barthes (1972) e Christopher Lasch (1979). Alguns pesquisadores do mercado também começam a agir nessa capacidade - como John Naisbitt (1982), Arnold Mitchell (1983) e, possivelmente, John Molloy (1977).

Esses grupos compartilham uma divisão relativamente igualitária do trabalho. Os jornalistas representam seu papel agindo como se fossem "porteiros" ou filtros. Avaliam as inovações estéticas, sociais e culturais no momento em que surgem e então classificam essas inovações como sendo efêmeras ou permanentes. Sob esse aspecto, os jornalistas assemelham-se aos "porteiros" dos mundos da arte (Becker, 1972) e da música (Hirsch, 1972). Os jornalistas devem observar da melhor maneira possível o turbilhão de inovações culturais e decidir o que é efêmero 
e o que irá durar. Depois de concluírem esse difícil processo de separar o joio do trigo, os jornalistas engajam-se num processo de disseminação para tornar conhecidas as suas decisões. É preciso admitir que todos os membros da cadeia de difusão (Rogers, 1983) representam o papel de "porteiros" e ajudam a influenciar o gosto das pessoas que buscam liderança de opinião. Os jornalistas são especialmente importantes porque sua influência se faz sentir antes mesmo que uma inovação chegue aos "primeiros usuários" (Baumgarten, 1975; Meyersohn e Katz, 1857; Polegato e Wall, 1980).

Quando os jornalistas identificam inovações genuínas, cabe aos projetistas de produto a tarefa de inserir esse significado dentro do sistema e investi-lo em bens de consumo. O projetista de produto difere do diretor de agência de publicidade na medida em que transforma não apenas as propriedades simbólicas de um bem de consumo, como também suas propriedades físicas. Afora os desfiles de moda e as feiras (que só atingem alguns consumidores em potencial), o projetista de produto não tem um contexto de significado, como o anúncio, onde exibir o bem de consumo. Pelo contrário, o bem de consumo sairá das mãos do projetista e entrará para qualquer contexto que o consumidor escolha. $\mathrm{O}$ projeto de produto é o meio que um projetista tem de convencer o consumidor de que um objeto específico possui um determinado significado cultural. O objeto deve sair das mãos do projetista com suas novas propriedades simbólicas claramente visíveis em suas novas propriedades físicas.

O projetista, como o diretor de agência, depende do consumidor para fornecer o ato final de associação e realizar a transferência de significado do mundo para o objeto. Mas, ao contrário do diretor de agência, o projetista de produto não tem à sua disposição as circunstâncias altamente administradas e retóricas do anúncio para incentivar e orientar essa transferência de significado. O projetista não é capaz de informar o consumidor das qualidades pretendidas do objeto; essas qualidades devem ser evidentes por si sós, de modo que o consumidor possa realizar a transferência de significado por conta própria. Assim, é necessário que o consumidor tenha acesso às mesmas fontes de informação sobre novas modas em significado que o projetista. O jornalista disponibiliza essas informações para o consumidor de tal maneira que este possa identificar a significância cultural das propriedades físicas de um novo objeto. Em suma, o projetista depende do jornalista no começo e, novamente, no fim do processo de transferência de significado. O jornalista fornece novo significado tanto ao projetista quanto ao recipiente do trabalho do projetista. Com isso, tanto a publicidade quanto o sistema de moda são instrumentos de transferência de significado do mundo culturalmente constituído para os bens de consumo. São dois dos meios pelos quais se investe de significado o código do objeto, sendo graças a eles que os objetos de nosso mundo trazem tamanha riqueza, variedade e versatilidade de significado, e nos podem servir de maneiras tão diversas em atos de autodefinição e comunicação social.

\section{LOCALIZAÇÕES DE SIGNIFICADO CULTURAL: BENS DE CONSUMMO}

O fato de serem os bens de consumo o locus do significado cultural é um fato bem estabelecido demais para exigir aqui uma demonstração elaborada. Eis o que Sahlins (1976, p. 179) tem a dizer sobre uma categoria de produtos - o vestuário:

Tomado como um todo, o sistema de vestuário americano representa um esquema altamente complexo de categorias culturais, e as relações entre elas, um verdadeiro mapa não seria exagero dizer - do universo cultural.

O que se pode dizer do vestuário aplica-se também à virtual totalidade de outras categorias de produtos de elevado envolvimento e a diversas categorias de baixo envolvimento. Vestuário, transportes, alimentos, exteriores, interiores e adornos residenciais servem como meio para a expressão do significado cultural que constitui nosso mundo.

O fato de os bens possuírem significado cultural é às vezes evidente e às vezes oculto para os consumidores. Estes podem perceber e manipular conscientemente significados culturais como o status de um item de consumo. Mas, com igual freqüência, os consumidores individuais só reconhecem o significado cultural embutido nos bens de consumo sob circunstâncias excepcionais. Por exemplo, os consumidores que tenham perdido bens por causa de roubo, empobrecimento súbito ou a alienação que decorre do envelhecimento, evidenciam um profundo senso de perda e, mesmo, de luto (Belk, 1982, p. 185). Os rituais de posse que discutiremos em breve também sugerem que as propriedades significativas dos bens de consumo nem sempre são conspícuas para o consumidor, por mais que sirvam par informar e controlar suas ações.

Vimos no começo deste artigo que a última década testemunhou uma enxurrada de trabalhos sobre o significado dos bens de consumo. De fato, a riqueza dessa literatura 
nos assegura que o estudo do significado cultural que os bens carregam é um desafio acadêmico florescente. Nada dessa literatura, contudo, aborda a questão da qualidade móvel do significado cultural, e poderia ser desejável fazer dessa questão uma premissa central no campo. Quando examinamos o significado cultural dos bens de consumo, podemos desejar determinar de onde vem o significado cultural e como foi transferido.

\section{INSTRUMENTOS DE TRANSFERÊNCIA DE SIGNIFICADO: DO BEM PARA O CONSUMIDOR}

Até este ponto acompanhamos o movimento do significado cultural do mundo culturalmente constituído para os bens de consumo, e consideramos o papel representado por dois instrumentos nesse processo. Passamos então a abordar como o significado, agora residente nos bens de consumo, se move do bem de consumo para a vida do consumidor. Para descrever esse processo, um segundo conjunto de instrumentos de transferência de significado precisa ser discutido. Esses instrumentos parecem qualificar-se, como casos especiais de "ação simbólica" ou ritual (Munn, 1973; Turner, 1969). O ritual é uma espécie de ação social dedicada à manipulação do significado cultural para fins de comunicação e categorização coletiva e individual. O ritual é uma oportunidade de afirmar, evocar, atribuir ou rever os símbolos e significados convencionais da ordem cultural. Nesse sentido, ele é uma ferramenta poderosa e versátil de manipulação do significado cultural. Na forma de um rito de passagem clássico, o ritual é usado para mover alguém de uma categoria cultural de pessoa para outra, onde abre mão de um conjunto de propriedades culturais, como as de uma criança, e assume outras, como as de um adulto (Turner, 1967; Van Gennep, 1960). Outras formas de ritual são dedicadas a diferentes fins sociais. Algumas são usadas para dar "realidade experiencial" a determinados princípios e conceitos culturais (Tambiah, 1977). Ainda outras são usadas para criar determinados contratos políticos (McCracken, 1982b). Em suma, o ritual atende a diversos fins em sua manipulação do significado cultural. Na América do Norte de hoje, o ritual é usado para transferir significado cultural dos bens para os indivíduos. São usados quatro tipos de ritual para esse fim: troca, posse, cuidados pessoais e alienação. Cada um deles representa um estágio diferente de um processo mais geral pelo qual o significado se move do bem de consumo para o consumidor individual.

\section{Rituais de troca}

Nos rituais de troca da América do Norte contemporâneaprincipalmente os de Natal e aniversário -, uma parte escolhe, compra e oferece bens de consumo à outra (Caplow, 1982). Essa movimentação de bens é também potencialmente uma movimentação de propriedades significativas. Muitas vezes quem dá o presente escolhe um item porque possui as propriedades significativas que deseja transferir ao recebedor do presente. Assim, a mulher que recebe um tipo específico de vestido é recebedora, também, de um conceito específico de si mesma como mulher (Schwartz, 1967). O vestido contém esse conceito, e quem dá o presente convida a recebedora a se definir nesses termos. Da mesma forma, muitos dos presentes contínuos que fluem entre pais e filhos são motivados exatamente por essa idéia. Os presentes dados à criança contêm propriedades simbólicas que o pai desejaria que ela assimilasse (Furby 1978, p. 312-313).

O ritual de troca de presentes estabelece um potente meio de influência interpessoal. A troca de presentes permite que os indivíduos insinuem determinadas propriedades simbólicas na vida do recebedor e iniciem uma possível transferência de significado. Em termos mais genéricos, os consumidores que atuam no papel de quem dá presentes se tornam agentes de transferência de significado na medida em que distribuem seletivamente bens com propriedades específicas a indivíduos que, de outra maneira, poderiam ou não escolhê-los. O estudo da troca de presentes, bem estabelecido nas ciências sociais (Davis, 1972; Mauss, 1970; McCracken, 1983; Sahlins, 1972), já está em andamento no campo da pesquisa de consumidores (Belk, 1979) e merece maior estudo. É preciso dar atenção ao processo de escolha usado por quem dá um presente para identificar o presente com os significados culturais que deseja passar ao recebedor. Também é preciso dar atenção à significância do embrulho e da apresentação do presente, além do contexto (momento e local) em que são feitas as apresentações. Esses aspectos do ritual doméstico da troca de presentes são de vital importância para as propriedades significativas dos bens trocados.

\section{Rituais de posse}

Os consumidores passam muito tempo limpando, discutindo, comparando, exibindo e até fotografando muitas de suas posses, ou mesmo refletindo sobre elas. As festas de abertura ou inauguração de um novo lar por vezes fornecem uma oportunidade de exibição, enquanto o processo de "personalização" (Hirschman, 1982, p. 37-38; Rapoport, 1968, 1982) age especialmente como ocasião 
para bastante comparação, reflexão e discussão. Embora essas atividades tenham uma função explícita, todas parecem ter o efeito adicional de permitir que o consumidor reclame a posse para si. Esse processo de reclamação não é uma simples afirmação de territorialidade por meio da propriedade. A reclamação é também uma tentativa de extrair do objeto as qualidades que lhe foram conferidas pelas forças de mercado do mundo dos bens. Esse processo é mais perceptível quando deixa de acontecer. Por exemplo, um consumidor pode às vezes afirmar que uma posse - um carro, uma casa, uma peça de vestuário "nunca pareceu ser minha de verdade". Há certos bens que o consumidor nunca reclama com sucesso porque nunca reclama com sucesso suas propriedades simbólicas. O bem de consumo torna-se um paradoxo: o consumidor é proprietário sem ter posse; as propriedades simbólicas do bem permanecem imóveis.

Normalmente, contudo, o indivíduo realiza com sucesso os rituais de pose e consegue extrair as propriedades significativas de que foi investido o bem de consumo. Se o significado cultural tiver sido transferido, os consumidores podem usar os bens como marcadores de tempo, espaço e ocasião. Os consumidores exploram a capacidade desses bens de discriminar entre categorias culturais como classe, status, gênero, idade, ocupação e estilo de vida. Uma vez que os rituais de posse permitem que o consumidor tome posse do significado de um bem de consumo, ajudam a concluir o segundo estágio da trajetória da movimentação do significado cultural. Como vimos, as agências de publicidade e o mundo da moda movem os significados do mundo culturalmente constituído para os bens de consumo. Por meio dos rituais de posse, as pessoas movem o significado cultural de seus bens para sua vida.

Vale observar que os rituais de posse, especialmente os que se dedicam à personalização do objeto, parecem quase representar, em pequena escala e para fins privados, as atividades de transferência de significado realizadas pela agência de publicidade. $\mathrm{O}$ ato de personalização é, na prática, uma tentativa de transferir significado do mundo próprio do indivíduo para o bem recém-adquirido. O novo contexto nesse caso é o estoque de bens de consumo do indivíduo, que assume um significado pessoal além de seu significado público. Com efeito, é talvez principalmente dessa maneira que uma posse anônima - criatura de um processo de fabricação em massa impessoal e distante se transforma em uma posse pessoal que pertence a alguém e fala por esse alguém. Talvez seja assim que os indivíduos criam um mundo pessoal de bens que reflete sua própria experiência e seus próprios conceitos de si e do mundo. O significado que a publicidade transfere aos bens é o significado da coletividade. O significado que os gestos pessoais transferem aos bens é o significado da coletividade na forma dada pela inflexão da experiência pessoal do consumidor individual.

\section{Rituais de cuidados pessoais}

Está claro que parte do significado cultural extraído dos bens é perecível. Com isso, o consumidor precisa extrair repetidamente significado cultural de suas posses. Quando se faz necessário um processo contínuo de transferência de significado dos bens para o consumidor, o consumidor provavelmente recorre a um ritual de cuidados pessoais. O objetivo desse ritual é tomar os cuidados necessários para garantir que as propriedades especiais e perecíveis residentes em determinadas roupas, cortes de cabelo e aparências sejam como que "ordenhadas" dos bens em que residem e trazidas à vida, ainda que breve e precariamente, no próprio consumidor individual. Os rituais para "sair" que adotamos quando nos preparamos para uma noitada são bons exemplos desse processo. Esses rituais ilustram o tempo, a paciência e a ansiedade com que uma pessoa se prepara para o escrutínio público especial de um baile de gala ou de um jantar. Os rituais de cuidados pessoais armam aqueles que vão "sair" com as propriedades glamourosas, exaltadas, significativas que há em seus "melhores" bens de consumo. Uma vez captadas e residentes numa pessoa, essas propriedades significativas lhe dão novos poderes de autoconfiança, agressão e defesa. A linguagem com que os anúncios descrevem determinados produtos de maquiagem, cuidados com o cabelo e vestuário reconhecem tacitamente as propriedades significativas disponíveis nos bens que são liberadas por rituais especiais de cuidados pessoais.

Contudo, às vezes não é o consumidor, mas o bem, que necessita de cuidados. Isso ocorre quando o consumidor cultiva as propriedades significativas de um objeto no próprio objeto em vez de ordenhar essas propriedades para si. A extraordinária quantidade de tempo e energia altamente redundante gasta com determinados automóveis talvez seja o melhor exemplo disso (Myers, 1985, p. 562). Esse tipo de ritual de cuidado sobrecarrega o objeto de maneira que ele possa, por sua vez, transferir propriedades especiais ampliadas a um proprietário. Aqui, mais uma vez, o papel do indivíduo ao investir significado fica evidente. A importância, para o consumidor, de cultivar bens de consumo que possam liberar suas qualidades significativas fica mais exacerbadamente manifesta no com- 
portamento de indivíduos em processo de envelhecimento. Sherman e Newman (1977-1978, p. 188) relatam que os moradores de casas de repouso que se consideram "no fim da linha" dedicam-se a um processo de "decatequese [remoção de significado emocional] de objetos significativos na vida deles".

No campo da pesquisa de consumo, o estudo do ritual foi significativamente avançado por Rook (1984). Ele observou o quanto o comportamento de consumo é ritualizado e percebeu que vale a pena estudar o consumo do ponto de vista ritual. Rook e Levy (1982) examinaram o ritual de cuidados pessoais e o simbolismo dos produtos de toucador. Fica claro que os rituais de cuidados pessoais é um dos meios pelos quais os indivíduos realizam uma transferência de propriedades simbólicas. Nos rituais de cuidados pessoais, o significado se move dos bens de consumo para o consumidor. Os rituais de cuidados pessoais ajudam a extrair significado cultural desses bens e investi-los no consumidor.

\section{Rituais de desapropriação}

As pessoas que extraem significado dos bens passam a enxergar essas fontes de significado em termos pessoais, associando os bens a suas propriedades pessoais. A possível confusão entre consumidor e bem de consumo incentiva o uso do ritual de alienação. Os rituais de desapropriação são usados para dois fins. Quando um indivíduo compra um bem que já pertenceu a outrem, como uma casa ou um carro, o ritual é usado para apagar o significado associado ao proprietário anterior. A desapropriação permite que o novo proprietário evite entrar em contato com as propriedades significativas do proprietário anterior e libere as propriedades significativas da posse, reclamando-as para si. O segundo ritual de desapropriação ocorre quando o indivíduo está para abrir mão de um bem, seja por doação ou por venda. $\mathrm{O}$ consumidor procurará apagar o significado de que foi investido o bem por associação. Em momentos de franqueza, as pessoas dizem sentir-se "pouco à vontade com outra pessoa usando meu velho casaco". Em momentos de franqueza ainda maior, confessarão que temem perder a posse de significado pessoal, um fenômeno que se assemelha à "fusão de identidades" que às vezes se dá entre os doadores e os recebedores de transplantes de órgãos (Simmons, Klein e Simmons, 1977, p. 68). Os dois rituais sugerem uma preocupação de que o significado dos bens possa ser transferido, confundido, ou mesmo perdido quando os bens mudam de mãos (Douglas, 1966). Assim, os bens devem ser esvaziados de significado antes de serem passados adiante, e esvaziados de significado ao serem assumidos. O que parece mera superstição é, na verdade, um reconhecimento implícito da qualidade móvel do significado com o qual os bens estão investidos.

Em suma, de diversas maneiras, os rituais pessoais são usados para transferir para os consumidores individuais o significado contido nos bens. Os rituais de troca são usados para transferir bens carregados de determinadas propriedades significativas às pessoas que delas necessitam, segundo presumem aqueles que dão o presente. Num ritual de troca, quem dá o presente convida o recebedor a compartilhar as propriedades que o bem possui. Os rituais de posse são praticados por um proprietário para recuperar as propriedades significativas de um bem. São concebidos para transferir as propriedades de um bem para seu proprietário. Os rituais de cuidados pessoais são usados para realizar a transferência contínua de propriedades perecíveis que se acredita tendem a desaparecer quando possuídas pelo consumidor. Permitem que o consumidor "atualize" as propriedades que extrai dos bens. Esses rituais também podem ser usados para manter e "avivar" determinadas propriedades significativas localizadas nos bens. Finalmente, os rituais de desapropriação são usados para esvaziar bens de significado de tal maneira que não possa ocorrer perda ou contágio de significado. Todos esses rituais são uma espécie de versão microcósmica dos instrumentos de transferência de significado que movem o significado do mundo para os bens, uma vez que esses rituais movem o significado dos bens para o consumidor.

\section{LOCALIZAÇÕES DE SIGNIFICADO CULTURAL: CONSUMIDORES INDIVIDUAIS}

O significado cultural é usado para definir e orientar o indivíduo de um modo que apenas começamos a compreender. Os indivíduos que vivem numa cultural industrial ocidental gozam de uma ampla gama de opções quanto ao significado que podem extrair dos bens. Observamos, no início deste artigo, que a cultura norteamericana contemporânea deixa indefinida boa parte do indivíduo. Uma das maneiras pelas quais os indivíduos satisfazem sua liberdade e cumprem a responsabilidade da autodefinição é por meio da apropriação sistemática das propriedades significativas dos bens. Evidentemente, a tarefa não é fácil e nem sempre bem-sucedida. Muitos indivíduos procuram nos bens uma espécie de significado que ali não existe. Outros procuram apropriar-se 
de espécies de significado às quais, por avaliação sociológica objetiva, não fazem jus. Ainda outros procuram constituir sua vida apenas em termos do significado dos bens. Todas essas patologias do consumidor ficam evidentes no comportamento de consumo moderno, e todas ilustram como o processo de transferência de significado pode dar errado em detrimento do indivíduo e da sociedade. Em circunstâncias normais, contudo, o indivíduo usa os bens de maneira livre de problemas para constituir partes cruciais de si mesmo e do mundo. A lógica, os imperativos e os detalhes desse processo de construção de si e do mundo por meio dos bens são enormemente carentes de atenção e só agora atraem estudos rigorosos. Nossa cultura estudou suas próprias crenças e práticas com uma plenitude e um entusiasmo inéditos no registro etnográfico. Com a mesma plenitude e o mesmo entusiasmo, fez das posses materiais uma de suas mais envolventes preocupações. É, portanto, duplamente estranho que o estudo do uso dos bens na construção de si mesmo e do mundo tenha sido objeto de tão prolongada e profunda negligência.

\section{SUMÁRIO}

Só recentemente o campo das relações "pessoa-objeto" fugiu às limitações a ele impostas por seu fundador, Thorstein Veblen. O campo começou a reconhecer que a importância do significado cultural que os bens de consumo carregam é muito mais variada e complexa do que imaginara Veblen. Sua insistência na importância do status acabou por impedir a percepção da dimensão cultural. Mas agora que o campo fez esse progresso, pode considerar a possibilidade de mais um avanço. Pode começar a levar em conta a qualidade alienável, móvel e manipulável do significado. Este artigo procurou encorajar tal desenvolvimento, fazendo uma apresentação teórica da estrutura e do movimento do significado cultural dos bens de consumo. Sugeriu que o significado reside em três localizações: o mundo culturalmente constituído, o bem de consumo e o consumidor. A publicidade, o sistema de moda e os rituais de consumo foram identificados como os meios por onde o significado é extraído e transferido entre eles. A publicidade e o sistema de moda movem para os bens de consumo o significado de um mundo culturalmente constituído, enquanto os rituais de consumo movem o significado do bem de consumo para o consumidor. Essa é a trajetória do movimento do significado cultural nas modernas sociedades desenvolvidas.

\section{AGRADECIMENTO}

$O$ autor agradece às seguintes pessoas por sua contribuição a este artigo: Michael Ames, Duncan Joy, Mary Ellen Roach-Higgins, K. O. L. Burridge, e aos revisores anônimos deste periódico.

\section{REFERÊNCIAS}

ADAMS, M. J. Structural aspects of a village art. American Anthropoligist, v. 75 , n. 1, p. 265-279, Feb. 1973.

ALLISON, N. K.; GOLDEN, L. L.; MULLER, G. M.; COOGAN, D. Sextype product images: the effects of sex, sex role self-concept and measurement implications. In: OLSON, J. C.; ARBOR, A. (Eds.). Advances in Consumer Research, v. 7. MI: Association for Consumer Research, 1980 p. 604-609.

APPADURAI, A. Gastro-politics in Hindu South Asia. American Ethnologist, v. 8, n. 3, p. 494-511, Aug. 1981.

ARLEN, M. J. Thirty Seconds. New York: Farrar, Straus and Giroux, 1980

AUSTIN, J. L. How to Do Things with Words. New York: Oxford University Press, 1963

BARBER, B.; LOBEL, L. Fashion in women's clothing and the american social system. In: BENDIZ, R.; LIPSET, S. M. (Eds.). Class, Status and Power New York: The Free Press, 1953. p. 323-332.

BARTHES, R. Elements of Semiology. New York: Hill e Wang, 1967. 
BARTHES, R. Mythologie. London: Jonathan Cape, 1972.

BARTHES, R. The Fashion System. New York: Hill e Wang, 1983.

BAUMGARTEN, S. A. The innovative communicator in the diffusion process. Journal of Marketing Research, v. 12, n. 1, p. 12-18, 1975.

BECKER, H. Art Worlds. Berkeley, CA: University of California Press, 1982.

BELK, R. W. Gift-giving behavior. In: SHETH, J. N. (Ed.). Research in Marketing, v. 2. Greenwich, CT: JA1 Press, 1979. p. 95-126.

BELK, R. Acquiring, possessing, and collecting: fundamental processes in consumer behavior. In: BUSH, R. F; HUNT, S. G. (Eds.). Marketing Theory: Philosophy of Science Perspectives. Chicago: American Marketing Association, 1982. p. 185-190.

BELK, R.; MAYER, R.; BAHN, K. The eye of the beholer: individual differences in perceptions of consumer symbolism. In: MITCHELL, A.; ARBOR, A. (Eds). Advances in Consumer Research, v. 9. MI: Association for Consumer Research, 1981. p. 523-530

BIRNBACH, L. The Official Preppy Handbook. New York: Workman Publishing, 1980.

BLUMBERG, P. The decline and fall of the status symbol: some thoughts on status in a post-industrial society. Social Problems, v. 21, n. 4, p. 480498,1974

BOURDIEU, P. The berber house. In: DOUGLAS, M. (Ed). Rules and Meanings. Harmondsworth, UK: Penguin Books, 1973. p. 98-100.

BRAUDEL, F. Capitalism and Material Life 1400-1800. London: Weidenfeld and Nicolson, 1973.

BRONNER, S. J. Visible proofs: material culture study in American folkloristics. American Quarterly, v. 35, n. 3, p. 316-338, 1983.

CAPLOW, T. Christmas gifts and kin networks. American Sociological Review, v. 47, n. 3, p. 383-392, 1982.

CLARK, C. E. Domestic architecture as an index to social history: the romantic revival and the cult of domesticity in America, 1840-1870. Journal of Interdisciplinary History, v. 7, p. 33-56, 1976.

COHEN, L. A. Embellishing a life of labour: an interpretation of the material culture of American-class homes. In: SCHLERETH, T. J. (Ed.). Material Culture Studies in America. Nashville, TN: The American Association for State and Local History, 1982. p. 289-395.

COLEMAN, R. P. The continuing significance of social class to marketing. Journal of Consumer Research, v. 10, n. 3, p. 265-280, 1983.
CSIKSZENTIMIHALYI, M.; ROCHBERG-HALTON, E. The Meaning of Things. Domestic Symbols and the Self. New York: Cambridge University Press, 1981.

CUNNIGHAM, C. E. Order in the Atoni House. In: NEEDHAM, R. (Ed.). Right and Left. Chicago: University of Chicago Press, 1973. p. 204-238.

DAVIS, J. Gifts and the UK economy. Man, v. 7, n. 3, p. 408-429, 1972.

DAVID, J. Status symbols and the measurement of status perception. Sociometry, v. 19, p. 154-165, Sep. 1956.

DAVID, J. Cultural factors in the perception of status symbols. The Midwest Sociologist, v. 21, p. 1-11, 1958.

DISMAN, M. Domestic possessions as manifestations of elderly immigrants' identity. Paper apresentado a 13a Assembléia Anual da Associação Canadense de Gerontologia, Vancouver, BC, Canada, 1984.

DOUGLAS, M. Purity and Danger: An Analysis of Concepts of Pollution and Taboo. Harmondsworth, UK: Penguin Books, 1966.

DOUGLAS, M. Deciphering a meal. In: GEERTZ, C. (Ed.). Myth, Symbol, and Culture. New York: W. W. Norton, 1971. p. 61-81.

DOUGLAS, M.; ISHERWOOD, B. The World of Goods: Towards and Anthropology of Consumption. New York: W. W. Norton, 1978.

DOXTATER, D. Spatial opposition in non-discursive expression: architecture as a ritual process. Canadian Journal of Anthropology, v. 4, n. 1, p. 1-17, 1984.

DREWAL, H. Body art as an expression of aesthetics and ontology among the Yoruba. Paper apresentado na sessão E-203 do $11^{\circ}$ Congresso Internacional de Ciências Antropológicas e Etnográficas. Vancouver, BC, Canada, 1983.

DURKHEIM, E.; MAUSS, M. Primitive Classification. Trad. Rodney Needham. Chicago: University of Chicago Press, 1963.

DYER, G. Advertising as Communication. New York: Methuen, 1982.

FALLERS, L. A. A note on the trickle effect. In: LIPSET, S. M.; SMELSER, N. (Eds.). Sociology: Progress of a Decade. Englewood Cliffs, NJ: PrenticeHall, 1961. p. 501-506.

FELSON, M. The differentiation of material life styles: 1925 to 1966. Social Indicators Research, v. 3, p. 397-421, 1976.

FERNANDEZ, J. W. Principles of opposition and vitality in fang aesthetics. Journal of Aesthetics and Art Criticism, v. 25, n. 1, p. 53-64, 1966.

FIELD, G. A. The status float phenomenon: the upward diffusion of innovation. Business Horizons, v. 13, p. 45-52, 1970 


\section{GRANT MCCRACKEN}

FORM, W.; STONE, G. Urbanism, anonymity and status symbolism. American Journal of Sociology, v. 62, n. 5, p. 504-514, 1957.

FOX, R. W.; LEARS, T. J. J. (Eds.). The Culture of Consumption: Critical Essays in American History, 1880-1990. New York: Pantheon Books, 1983

FRASER, K. The Fashion Mind. New York: Alfred A. Knopf, 1981.

FURBY, L. Possessions: toward a theory of their meaning and function throughout the life cycle. In: BALTES, P. B. (Ed.). Lifespan Development and Behavior. New York: Academic Press, 1978. p. 297-336.

GARFINKLE, A. D. A sociolinguistic analysis of the language of advertising. Dissertação inédita, Departamento de Lingüística, Georgetown University, Washington, DC. 20057, 1978.

GOFFMAN, E. Symbols and class status. British Journal of Sociology, v. 2, p. 295-304, 1951.

GOFFMAN, E. Gender Advertisement. Cambridge, MA: Harvard University Press, 1979

GRAUMANN, C. F. Art as a structural system: a study of Hopi pottery designs. Studies in the Anthropology of Visual Communication, v. 2, n. 1, p. 33-60, 1974-1975.

HALL, E. T. The Dance of Life. The Other Dimension of Time. Garden City, NY: Anchor Press, 1983.

HEBDIGE, D. Subculture: The Meaning of Style. London: Methuen, 1979

HIRSCHMAN, P. M. Processing fads and fashions: an organization-set analysis of cultural industry systems. American Journal of Sociology, v. 77, n. 4, p. 639-659, 1972.

HIRSCHMAN, A. O. Shifting Involvements. Princeton, NJ: Princeton University Press, 1982.

HIRSCHMAN, E. C. Comprehending symbolic consumption. In: HIRSCHMAN, E. C.; HOLBROOK, M. B. (Eds.). Symbolic Consumer Behavior. Ann Arbor, MI: Association for Consumer Research, p. 4-6, 1982

HIRSCHMAN, E. C. Leisure motives and sex roles. Journal of Leisure Research, v. 16, n. 3, p. 209-223, 1984.

HOLMAN, R. Product use as communication: a fresh appraisal of a venerable topic. In: ENIS, B. M.; ROERING, K. J. (Eds.). Review of Marketing. Chicago: American Marketing Association, p. 250-272, 1980.

KRON, J. Home-Psych The Social Psychology of Home and Decoration. New York: Clarkson N. Potter, 1983.
LASCH, C. The Culture of Narcissism. New York: W. W. Norton, 1979.

LAUMANN, E. O.; HOUSE, J. S. Living room styles and social attributes: the patterning of material artifacts in a modern urban community. Sociology and Social Research, v. 54, p. 321-342, 1970.

LECHTMAN, H.; MERRIL, R. S. (Eds.). Material Culture: Styles, Organization and Dynamics of Technology, St. Paul, MN: West, 1977.

LEISS, W. Things come alive: economy and technology as modes of social representation in modern society. Artigo apresentado à Mesa Redonda sobre Representações, Montréal, Quebec, Canada, 1983.

LEVI-STRAUSS, C. The Savage Mind, Chicago: University of Chicago Press, 1966.

LEVY, S. Symbols for sale. Harvard Business Review, v. 37, p. 117-124 1959.

LEVY, S. Hunger and work in a civilized tribe. American Behavior Scientist, v. 21, p. $557-570,1978$

LEVY, S. Interpreting consumer mythology: a structural approach to consumer behavior. Journal of Marketing, v. 45, p. 49-61, 1981.

LOHOF, B. The highest meaning of Marlboro cigarettes. Journal of Popular Culture, v. 3, n. 3, p. 441-450, 1969.

MARTIN, B. A Sociology of Contemporary Cultural Change. Oxford, UK Basil Blackwell, 1981.

MAUSS, M. The Gift. London: Routledge and Kegan Paul, 1970.

MCCRACKEN, G. Rank and two aspects of dress in Elizabethan England. Culture, v. 2, n. 2, p. 53-62, 1982a.

MCCRACKEN, G. Politics and ritual sotto voce: the use of demeanor as an instrument of politics in Elizabethan England. Canadian Journal of Anthropology, v. 3, p. 85-100, 1982b.

MCCRACKEN, G. The exchange of Tudor children. Journal of Family History, v. 8, p. 303-313, 1983.

MCCRACKEN, G. Anthropology and the study of advertising: a critical review of selected literature. Working Paper $n^{\circ}$ 84-103. Department of Consumer Studies, University of Guelph, Guelph, Ontario, Canada, 1984.

MCCRACKEN, G. Consumer goods and cultural meaning? A theoretical account of the substantiation of cultural categories and principles in consumer goods. Working Paper no 85-102. Department of Consumer Studies, University of Guelph, Guelph, Ontario, Canada, 1985a. 
MCCRACKEN, G. Consumer goods and cultural change: A theoretical account of change in the cultural meaning of consumer goods. Working Paper no 85-104. Department of Consumer Studies, University of Guelph, Guelph, Ontario, Canada, 1985b.

MCCRACKEN, G. The Trickle-Doen theory rehabilitated. In: SOLOMON, M. R. (Ed.). The Psychology of Fashion. Lexington, MA: Lexington Books, 1985c. p. 39-45.

MCCRACKEN, G. The making of modern consumption behavior: The historical origins and development of the context and activity of modern consumption. Working Paper n ${ }^{\circ}$ 85-101. Department of Consumer Studies, University of Guelph, Guelph, Ontario, Canada, 1985d.

MCCRACKEN, G. Clothing as language: an object lesson in the study of the expressive properties of material culture. In: REYNOLDS, B; STOTT, M. (Eds.). Material Anthropology: Contemporary Approaches to Material Culture. New York: University Press of America, no prelo, 1986.

MCKENDRICK, N.; BREWER, J.; PLUMB, J. H. The Birth of a Consumer Society: The Commercialization of Eighteenth Century England. Bloomington, IN: Indiana University Press, 1982.

MEIKLE, J. L. Twentieth Century Limited: Industrial Design in America 1925-1939. Philadelphia: Temple University Press, 1979.

MEYERSON, R.; KATZ, E. Notes on a natural history of fads. American Journal of Sociology, v. 62, p. 594-601, 1957.

MITCHELL, A. The Nine American Lifestyles. New York: Warner Books, 1983.

MOERAN, B. When the poetics of advertising becomes the advertising of poetics: syntactical and semantic parallelism in English and Japanese advertising. Language and Communication, v. 5, n. 1, p. 29-44, 1985.

MOLLOY, J. T. The Women's Dress for Success Book. New York: Warner Books, 1977.

MUNN, N. Symbolism in a ritual context: aspects of symbolic action. In: HONIGMANN, J. L. (Ed.). Handbook of Social and Cultural Anthropology. Chicago: Rand McNally, 1973. p. 579-612.

MYERS, E. Phenomenological analysis of the importance of special possessions: an exploratory study. In: HIRSCHMAN, E. C.; MORRIS, B. (Eds.). Advances in Consumer Research, Vol. 12. Holbrook, Provo, UT: Association for Consumer Research, 1985. p. 560-565.

NAISBITT, J. Megatrends. New York: Warner Books, 1982.

NICOSIA, F. M.; MAYER, R. N. Toward a sociology of consumption. Journal of Consumer Research, v. 3, n. 2, p. 65-75, 1976.
OLSON, C. D. Materialism in the home: the impact of artifacts in dyadic communication. In: HIRSCHMAN, E. C.; HOLBROOK, M. B. (Eds.). Advances in Consumer Research, v. 12. Holbrook, Provo, UT: Association for Consumer Research, 1982.

ORTNER, S. Sherpas Through their Rituals. Cambridge, UK: Cambridge University Press, 1978.

POLEGATO, R.; WALL, M. Information seeking by fashion opinion leaders and followers. Home Economics Research Journal, v. 8, n. 5, p. $327-$ 338,1980

PROWN, J. D. Style as evidence. Winterthur Portfolio, v. 15, n. 3, p. $197-$ 210,1980 .

PROWN, J. D. Mind in matter: an introduction to material culture theory and method. Winterthur Portfolio, v. 17, n. 1, p. 1-19, 1982.

PULOS, A. J. American Design Ethic: A History of Industrial Design to 1940. Cambridge, MA: M.I.T. Press, 1983.

QUIMBY, I. (Ed.). Material Culture and the Study of Material Life. New York: W. W. Norton, 1978.

RAPOPORT, A. The personal element in housing - an argument for openended design. Journal of the Royal Institute of British Architects, v. 75, p. 300-3017, 1978

RAPOPORT, A. Meanings of the Built Environment. Beverly Hills, CA: Sage Publications, 1982.

ROGERS, E. Diffusion of Innovations. New York: The Free Press, 1983.

RODMAN, M.; PHILIBERT, J. M. Rethinking consumption: some problems concerning the practice of objects in the third world. Paper apresentado às reuniões da Canadian Ethonological Society, University of Toronto, Ontario, Canada, 1985.

ROOK, D. Ritual behavior and consumer symbolism. In: HIRSCHMAN, E. C.; HOLBROOK, M. B. (Eds.). Advances in Consumer Research. Vol. 12 Provo, UT: Association for Consumer Research, 1984. p. 279-274.

ROOK, D.; LEVY, S. J. The psycho-social themes in grooming rituals. In: BAGOZZI, R. T.; THYBOUT, A. M. (Eds.). Advances in Consumer Research. Vol. 10. Ann Arbor, MI: Association for Consumer Research, 1982. p. 329-334

SAHLINS, M. The spirit of the gift. In: SAHLINS, M. (Ed.). Stone-Age Economics. Chicago: Aldine, 1972. p. 149-183.

SAHLINS, M. Culture and Practical Reason. Chicago: University of Chicago Press, 1976.

SAUSSURE, F. DE Course in General Linguistics. New York: McGraw-Hill, 1966 
SCHLERETH, T. J. Material culture studies in America, 1876-1976. In: SCHLERETH, T. J. (Ed.). Material Culture Studies in America. Nashville, TN: The America Association for State and Local History, 1982. p. 1-75.

SCHWARTZ, B. The social psychology of the gift. American Journal of Sociology, v. 73, n. 1, p. 1-11, Jul. 1967.

SCHWARZ, R. A. Uncovering the secret vice: toward an anthropology of clothing and adornment. In: CORDWELL, J.; SCHWARZ, R. (Eds.). The Fabrics of Culture. The Hague, Holland: Mouton, 1979.

SHERMAN, E.; NEWMAN, E. S. The meanings of cherished possessions for the elderly. International Journal of Aging and Human Development, v. 8, n. 2, p. 181-192, 1977-1978.

SHERRY, J. Advertising as a cultural system. Artigo apresentado à Conferência de Educadores da American Marketing Association, Phoenix, AZ, 1985.

SIMMEL, G. Fashion. International Quarterly, v. 10, n. 1, p. 130-155, 1904.

SIMMONS, R. G.; KLEIN, S. D.; SIMMONS, R. L. Gift of Life: The Social and Psychological Impact of Organ Donation. New York: John Wiley, 1977.

SOLOMON, M. The role of products as social stimuli: a symbolic interactionism perspective. Journal of Consumer Research, v. 10, n. 3, p. 319329, 1983.

SOMMERS, M. Product symbolism and the perception of social strata. In: GREYSER, S. A. (Ed.). Toward Scientific Marketing. Chicago: American Marketing Association, 1963. p. 200-216.
TAMBIAH, S. J. The cosmological and performative significance of a Thai cult of healing through mediation. Culture, Medicine and Psychiatry, v. 1, p. 97-132, 1977.

TURNER, T. Tchikrin, a central Brazilan tribe and its symbolic language of bodily adornment. Natural History, v. 78, n. 8, p. 50-59, Oct. 1969

TURNER, V. Betwixt and between: the liminal period in rites of passage. In: TURNER, V. (Ed.). The Forest of Symbols. Ithaca, NY: Cornell University Press, 1967. p. 93-111.

TURNER, V. Forms of symbolic action. In: SPENCER, R. F. (Ed.). Forms of Symbolic Action. Seattle, WA: American Ethnological Society, 1969. p. $3-25$.

UNRUH, D. R. Death and personal history: strategies of identity preservations. Social Problems, v. 30, n. 3, p. 340-351, 1983.

VAN GENNEP, A. The Rites of Passage. London: Routledge and Kegan Paul, 1960

VERSHURE, B.; MAGEL, S.; SADALLA, E. K. House form and social identity. In: SUEDFELD, P.; RUSSEL, J. A.; WARD, L. M.; SZIGETI, F; DAVIS, G. (Eds.). The Behavioral Basis of Design. Book 2. Stroudsburg, PA: Dowden, Hutchinson \& Ross, 1977. p. 273-278.

WILLIAMSON, J. Decoding Advertising. New York: Marion Boyars, 1978.

WOLFE, T. Radical Chic and Mau-Mauing the Flak Catchers. New York: Farrar, Straus and Giroux, 1970.

WARNER, L.; LUNT, P. S. The Social Life of a Modern Community. New Haven, CT: Yale University Press, 1941.

YORK, P. Style Wars. London: Sidgwich and Jackson, 1980

\section{Artigo convidado. Aprovado em 01.02.2006.}

\section{Grant McCracken}

Professor da Harvard Business School.

Interesse de pesquisa nas áreas de antropologia do consumo, antropologia

e economia, marketing.

E-mail: grant27@gmail.com

Blog: <http://www.cultureby.com/> 